\title{
MAX-DOAS retrieval of aerosol extinction properties in Madrid, Spain
}

\author{
Shanshan Wang ${ }^{1, a}$, Carlos A. Cuevas ${ }^{1}$, Udo Frie $\beta^{2}$, and Alfonso Saiz-Lopez ${ }^{1}$ \\ ${ }^{1}$ Department of Atmospheric Chemistry and Climate, Institute of Physical Chemistry Rocasolano, \\ CSIC, 28006 Madrid, Spain \\ ${ }^{2}$ Institute of Environmental Physics, University of Heidelberg, 69120 Heidelberg, Germany \\ ${ }^{a}$ now at: Shanghai Key Laboratory of Atmospheric Particle Pollution and Prevention $\left(\operatorname{LAP}^{3}\right)$, \\ Department of Environmental Science \& Engineering, Fudan University, 200433 Shanghai, China
}

Correspondence to: Shanshan Wang (swang@iqfr.csic.es; shanshanwang@fudan.edu.cn)

Received: 25 March 2016 - Published in Atmos. Meas. Tech. Discuss.: 14 April 2016

Revised: 22 September 2016 - Accepted: 26 September 2016 - Published: 18 October 2016

\begin{abstract}
Multi-axis differential optical absorption spectroscopy (MAX-DOAS) measurements were performed in the urban environment of Madrid, Spain, from March to September 2015. The $\mathrm{O}_{4}$ absorption in the ultraviolet (UV) spectral region was used to retrieve the aerosol extinction profile using an inversion algorithm. The results show a good agreement between the hourly retrieved aerosol optical depth (AOD) and the correlative Aerosol Robotic Network (AERONET) product, with a correlation coefficient of $R=0.87$. Higher AODs are found in the summer season due to the more frequent occurrence of Saharan dust intrusions. The surface aerosol extinction coefficient as retrieved by the MAX-DOAS measurements was also compared to in situ $\mathrm{PM}_{2.5}$ concentrations. The level of agreement between both measurements indicates that the MAX-DOAS retrieval has the ability to characterize the extinction of aerosol particles near the surface. The retrieval algorithm was also used to study a case of severe dust intrusion on 12 May 2015. The capability of the MAX-DOAS retrieval to recognize the dust event including an elevated particle layer is investigated along with air mass back-trajectory analysis.
\end{abstract}

\section{Introduction}

Atmospheric aerosols, with variable size ranging from a few nanometers to tens of micrometers in diameter, have an influence on the atmospheric radiative budget, global climate change, local air quality and visibility, as well as directly or indirectly on human health (Seinfeld and Pandis, 2006; Kim and Ramanathan, 2008; Levy et al., 2013; Viana et al., 2014; Karanasiou et al., 2012). Moreover, aerosol properties and vertical distribution vary greatly with geographical location. Therefore, it is important to obtain a comprehensive knowledge on the spatiotemporal distribution of aerosol characteristics in terms of chemical composition and physical properties. Measurements of aerosol optical and physical properties, including the aerosol extinction coefficient (AEC), aerosol optical depth (AOD) and single scattering albedo (SSA), provide information for a better understanding of the role of aerosols in atmospheric processes. Additionally, more accurate vertically resolved measurements of aerosol optical properties are still needed to further assess the aerosol environmental and radiative effects (IPCC, 2013).

Based on molecular ultraviolet-visible (UV-VIS) light absorption, the differential optical absorption spectroscopy (DOAS) remote sensing technique is an effective tool for air pollution measurements (Platt and Stutz, 2008). By observing scattered sunlight at several elevations close to horizon and at zenith, multi-axis DOAS (MAX-DOAS) is capable of retrieving information of the vertical distribution of numerous trace gases (Hönninger et al., 2004; Wittrock et al., 2004). Since the oxygen collision complexes $\mathrm{O}_{4}$ vertical profile is well known and nearly constant, the observed $\mathrm{O}_{4}$ absorption can serve as an indicator for the atmospheric distribution of photon paths (Wagner et al., 2004; Frieß et al., 2006). Therefore, the retrieved $\mathrm{O}_{4}$ differential slant column densities (DSCDs) at different elevations can provide 


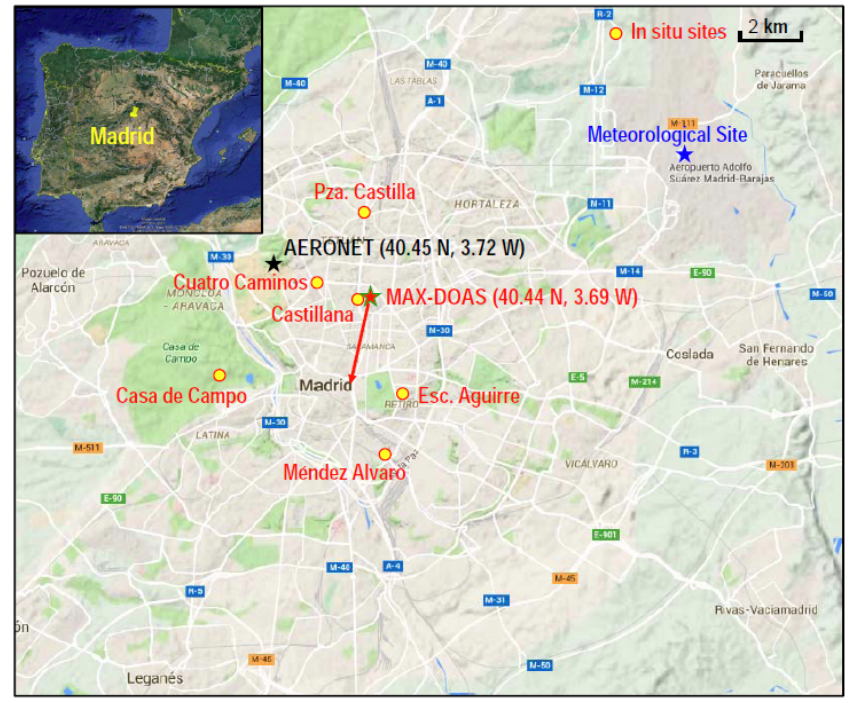

Figure 1. Location of the measurement sites in Madrid.

information about the impact of aerosol scattering on photon paths. By combining measurements of the $\mathrm{O}_{4}$ absorption with radiative transfer model simulations, ground-based MAX-DOAS has been used in previous studies to determine atmospheric aerosol vertical extinction profiles and optical depths (e.g., Irie et al., 2008, 2009; Li et al., 2010; Clémer et al., 2010; Hartl and Wenig, 2013; Hendrick et al., 2014; Vlemmix et al., 2015; Frieß et al., 2016).

Madrid, the capital of Spain, located in the southwest of Europe, is the third largest city in the European Union. The city of Madrid covers a total area of $604.3 \mathrm{~km}^{2}$. The residential population is almost 3.2 million, with a metropolitan area population of around 6.5 million. Due to the dense population and traffic, the city of Madrid has, in recent years, suffered severe levels of air pollution by nitrogen dioxide and occasionally by suspended particulates and ozone (Ayuntamiento de Madrid (AM), Madrid's Air Quality Plan 20112015, 2012). Air pollution episodes in the Madrid air basin are generally caused by local traffic emissions and domestic heating in winter (Plaza et al., 2011). The Madrid metropolitan area is bordered to the north-northwest by a high mountain range about $40 \mathrm{~km}$ away from the city and to the northeast and east by lower mountainous terrain. This specific topography results in particular meteorological conditions and typical transport patterns that significantly influence air pollution dynamics in Madrid (Salvador et al., 2008). In addition, the city of Madrid also suffers from significant aerosol contributions from natural sources, e.g., occasional Saharan dust intrusions.

To meet the current legislation targets on air quality, a new monitoring network of in situ instruments for $\mathrm{NO}_{2}, \mathrm{SO}_{2}$, $\mathrm{CO}, \mathrm{O}_{3}, \mathrm{PM}_{10}$ and $\mathrm{PM}_{2.5}$ has been operational in Madrid since 2010. This monitoring network comprises 24 automatic measuring stations and two additional sampling points for
$\mathrm{PM}_{2.5}$ suspended particulates. The in situ $\mathrm{PM}_{2.5}$ concentrations are measured at six stations as shown in Fig. 1, i.e., Esc. Aguirre, Casa de Campo, Quatro Caminos, Méndez Alvaro, Castellana and Pza. Castellana. Only a few studies have reported measurements of vertical aerosol optical properties in Madrid using lidar systems over short periods of time (Molero et al., 2014; Fernández et al., 2014).

Here we present aerosol optical properties in the urban center of Madrid, Spain, retrieved from MAX-DOAS observations of $\mathrm{O}_{4}$ in the $\mathrm{UV}$ spectral region. This is the first time that measurements of aerosol extinction properties in Madrid have been reported for several months, allowing investigation of the temporal variation of aerosol optical properties in the urban area. We compare the AOD and surface aerosol extinction coefficient retrieved from MAX-DOAS with correlative sun photometer data and in situ $\mathrm{PM}_{2.5}$ concentrations. Finally, we explore a case study of the aerosol optical properties during an intrusion of Sahara dust arriving in Madrid, which demonstrates the MAX-DOAS measurements as a useful monitoring tool to obtain vertically revolved aerosol optical properties during dust episodes.

\section{Measurements and method}

\subsection{MAX-DOAS instrument and setup}

Our MAX-DOAS instrument consists of three main parts, i.e., the scanning system, the spectrometer-detector equipment and the computer as the control unit (e.g., Mahajan et al., 2012; Prados-Roman et al., 2015). The scanning telescope was driven by a stepper motor to collect scattered sunlight from different elevation angles. The light is focused by a lens $(F=200 \mathrm{~mm})$ with a diameter of $50.8 \mathrm{~mm}$ to a bundle of 15 individual quartz fibers. The light is fed by the fiber bundle to a Princeton Instruments SP500i spectrometer with a Princeton Instruments Pixis 400B chargecoupled device (CCD) camera. The light is dispersed by a 600 grooves $\mathrm{mm}^{-1}$ grating, resulting in a spectral window of $90 \mathrm{~nm}$ and spectral resolution of $0.5 \mathrm{~nm}$ full width at half maximum (FWHM). The computer is responsible for running the overall system and storing the spectral data. During the spectra recording process, the offset was removed automatically. The signal of dark current was measured every night and subtracted from each spectrum according to the corresponding average exposure time. Depending on the intensity of the received scattered sunlight, the exposure time was adapted automatically between 0.1 and $1 \mathrm{~s}$ in order to optimize the total signal and avoid saturation.

Ground-based MAX-DOAS measurements were carried out from 15 March to 15 September 2015. The telescope scanning system was mounted on the top roof of a $25 \mathrm{~m}$ tall building at the main campus of the Spanish National Research Council (CSIC, $40.44^{\circ} \mathrm{N}, 3.69^{\circ} \mathrm{W} ; 700 \mathrm{~m}$ a.s.l.) in Madrid, Spain (see Fig. 1). The spectra were recorded with 
Table 1. DOAS retrieval settings for $\mathrm{O}_{4}$.

\begin{tabular}{ll}
\hline Parameter & Specification \\
\hline $\begin{array}{l}\text { Fitting window } \\
\text { Wavelength calibration }\end{array}$ & $\begin{array}{l}\text { 339-387 nm } \\
\text { Calibration based on reference solar atlas (Chance and Kurucz, 2010) }\end{array}$ \\
\hline Cross sections & \\
$\mathrm{O}_{4}$ & $293 \mathrm{~K}$, Thalman and Volkamer (2013) \\
$\mathrm{HCHO}$ & $298 \mathrm{~K}$, Meller and Moortgat (2000) \\
$\mathrm{O}_{3}$ & 223 and 243 K, I-corrected, Serdyuchenko et al. (2014) \\
$\mathrm{NO}_{2}$ & $294 \mathrm{~K}, \mathrm{I}_{0}$-corrected, Vandaele et al. (1998) \\
$\mathrm{BrO}$ & $223 \mathrm{~K}$, Fleischmann et al. (2004) \\
\hline Ring & Calculated with QDOAS \\
Additional adjustment & All spectra shifted and stretched against the reference spectrum \\
Polynomial order & 5 \\
Intensity offset & Linear correction \\
\hline
\end{tabular}

an elevation angle sequence of $-4,-2,0,1,3,5,7,10,20$, 30 and $90^{\circ}$ for each scanning cycle. After each completed cycle, the grating was shifted between the UV and VIS spectral regions, centered at 350 and $440 \mathrm{~nm}$, respectively. The telescope was pointed approximately to the south-southeast (around $206^{\circ}$ azimuth angle, red arrow in Fig. 1), towards the city center of Madrid. This measurement site is located in the downtown area of Madrid and is classified as a typical urban site, where the air quality is mainly impacted by nearby traffic emissions.

\subsection{Spectral analysis}

The $\mathrm{O}_{4}$ DSCDs were derived from UV spectra covering 305 to $395 \mathrm{~nm}$ for the retrieval, and only few data from VIS spectra were available due to the instrument problem. The QDOAS software developed by BIRA-IASB (http:// uv-vis.aeronomie.be/software/QDOAS/) was applied to analyze $\mathrm{O}_{4}$ absorption in the interval between 339 and $387 \mathrm{~nm}$, encompassing the three absorption bands at 343, 360 and $380 \mathrm{~nm}$. Trace gas absorption cross sections for $\mathrm{O}_{4}$ (Thalman and Volkamer, 2013), $\mathrm{NO}_{2}$ (Vandaele et al., 1998) and $\mathrm{O}_{3}$ (Serdyuchenko et al., 2014) at 223 and $243 \mathrm{~K}$, BrO (Fleischmann et al., 2004) and HCHO (Meller and Moortgat et al., 2000) and a synthetic ring spectrum (calculated by QDOAS) were included in the spectral fitting analysis. During each measurement cycle, the corresponding zenith spectrum was taken as a Fraunhofer reference spectrum for the lower viewing elevation angles. The relevant configuration for the spectral analysis is listed in Table 1. Afterwards, the $\mathrm{O}_{4}$ DSCDs were introduced into the aerosol retrieval algorithm if relative errors yielded from QDOAS are less than $10 \%$.

\subsection{Other datasets}

Cloud-screened AOD level 1.5 products from a CIMEL sun photometer situated on the roof of the Agencia Estatal de Meteorologia in Madrid, Spain (40.45 ${ }^{\circ}$, 3.72 ${ }^{\circ} \mathrm{W} ; 680 \mathrm{~m}$ a.s.1.), with a distance of $3.8 \mathrm{~km}$ from our measurements site (see Fig. 1) are compared to the column-integrated aerosol profile retrieved from MAX-DOAS measurements. The sun photometer is part of AERONET (Aerosol Robotic Network, http://aeronet.gsfc.nasa.gov/), which provides standards for instruments, calibration techniques, processing and data distribution (Holben et al., 1998). The AERONET data are automatically cloud-screened if the direct view of the sun is blocked by clouds. Thus, the absence of AERONET data can serve as a temporal index for the presence of clouds and further help to filter the MAX-DOAS measurements (Smirnov et al., 2000). The AOD at wavelengths of 340, 380, 440, 500, 675,870 and $1020 \mathrm{~nm}$ are available from the AERONET database at the Madrid site.

Additionally, time series of $\mathrm{PM}_{2.5}$ concentrations measured by in situ instruments were acquired from the air quality network of the Integral System of Air Quality Madrid City Council (http://www.mambiente.munimadrid.es) and were used to compare surface $\mathrm{PM}_{2.5}$ concentrations with the surface aerosol extinction coefficient derived by the MAXDOAS instrument. The six automatic measuring stations are located throughout the urban area of Madrid (see Fig. 1).

Meteorological data, including temperature, relative humidity, wind speed and wind direction, with a temporal resolution of $30 \mathrm{~min}$, were obtained from the Adolfo Suárez Madrid-Barajas Airport meteorological site $\left(40.47^{\circ} \mathrm{N}\right.$, $3.56^{\circ} \mathrm{W}$; see Fig. 1) (http://www.wunderground.com). All data are normalized to $1 \mathrm{~h}$ averages.

\section{The HEIPRO aerosol retrieval algorithm}

\subsection{Basic principle}

Since the zenith spectrum of each elevation sequence was taken as the reference, the DSCDs at lower elevations are sensitive to the trace gases in the lower troposphere. For the aerosol retrieval, $\mathrm{O}_{4}$ DSCDs from different elevations 
derived from the MAX-DOAS spectral analysis are fed into the aerosol inversion algorithm along with local atmospheric vertical pressure, temperature profiles and a suitable aerosol a priori profile. In this study, the HEIdelberg PROfile (HEIPRO, developed by IUP Heidelberg, Frieß et al., 2006, 2011) retrieval algorithm, with the SCIATRAN radiative transfer scheme (Rozanov et al., 2005) as forward model, was used for the retrieval of aerosol vertical profiles.

Based on the well-established optimal estimation method (OEM) (Rodgers, 2000), the HEIPRO algorithm determines the most probable atmospheric state $\boldsymbol{x}$ (aerosol extinction coefficient at a series of discrete altitude intervals) given a set of measurement $\boldsymbol{y}_{\mathrm{m}}$ and a priori state vector $\boldsymbol{x}_{\mathrm{a}}$. The so-called maximum a posteriori (MAP) solution $\hat{\boldsymbol{x}}$ is approached by minimizing the cost function (Frieß et al., 2006, 2011, 2016):

$$
\begin{aligned}
\chi^{2}(\boldsymbol{x})= & {[\boldsymbol{y}-F(x, b)]^{\mathrm{T}} \mathbf{S}_{\epsilon}^{-1}[\boldsymbol{y}-F(x, b)] } \\
& +\left[\boldsymbol{x}-\boldsymbol{x}_{\mathrm{a}}\right]^{\mathrm{T}} \mathbf{S}_{\mathrm{a}}^{-1}\left[\boldsymbol{x}-\boldsymbol{x}_{\mathrm{a}}\right],
\end{aligned}
$$

where the $m$-dimensional vector $\boldsymbol{x}$ defines the state of interest within the measured system. The radiative transfer model or forward function $F(x, b)$ simulates the corresponding modeled value for the atmospheric state $\boldsymbol{x}$, which is also dependent on the parameters $b$ including temperature, pressure and aerosol profiles etc. $\boldsymbol{y}$ denotes the measurement vector, i.e., measured $\mathrm{O}_{4}$ DSCDs at different elevation angles in the case of the aerosol profile retrieval. The a priori state vector $\boldsymbol{x}_{\mathrm{a}}$ serves as an additional constraint. $\mathbf{S}_{\epsilon}$ and $\mathbf{S}_{\mathrm{a}}$ denote the diagonal measurement covariance matrices, representing the uncertainties in the measurement and the a priori state, respectively.

The optimal state $\hat{\boldsymbol{x}}$, which minimizes $\chi^{2}$, can be found using the Levenberg-Marquardt method. The vertical resolution of the retrieval and the sensitivity of the retrieved state $\hat{\boldsymbol{x}}$ to the true atmospheric state $\boldsymbol{x}$ is quantified by the averaging kernel matrix $\mathbf{A}=\partial \hat{\boldsymbol{x}} / \partial \boldsymbol{x}$. The retrieved profile $\hat{\boldsymbol{x}}$ can be represented as the true profile $\boldsymbol{x}$, smoothed by the averaging kernel matrix A according to following Eq. (2):

$\hat{\boldsymbol{x}}=\boldsymbol{x}_{\mathrm{a}}+\mathbf{A}\left(\boldsymbol{x}-\boldsymbol{x}_{\mathrm{a}}\right)$

Apart from the retrieval of aerosol properties, the HEIPRO algorithm can also yield the vertical profile of trace gases by combining the resulting aerosol extinction profiles, serving as forward modeling parameters, with measured DSCDs and a priori profiles of trace gases. However, this paper only focuses on the aerosol retrieval.

\subsection{Aerosol inversion}

In the forward radiative transfer model, atmospheric pressure and temperature profiles were adapted from the climatological database employed in SCIATRAN, which contains monthly and latitudinal-dependent vertical distribution of atmospheric trace gases, pressure and temperature. The surface albedo was set to 0.1 for the Madrid urban area. Aerosol extinction profiles from the surface up to $4 \mathrm{~km}$ height were retrieved on a vertical resolution of $100 \mathrm{~m}$ with a fixed temporal interval of $15 \mathrm{~min}$. As to aerosol optical properties, the single scattering albedo and the asymmetry parameter for a Henyey-Greenstein phase function parameterization around $360 \mathrm{~nm}$ were set to 0.95 and 0.72 in the retrieval scheme, respectively. According to recently measured aerosol loadings in the Madrid downtown area, the annual averages of surface $\mathrm{PM}_{2.5}$ and $\mathrm{PM}_{10}$ in 2014 were around 10.8 and $19.4 \mu \mathrm{g} \mathrm{m}^{-3}$, respectively (Calidad del Aire Madrid, 2014), and monthly averaged AOD at $440 \mathrm{~nm}$ ranged from 0.07 to 0.17 . Based on these data, an a priori aerosol extinction profile, with a surface extinction coefficient of $0.05 \mathrm{~km}^{-1}$ and exponentially decreasing with scaling height of $1.5 \mathrm{~km}$, was assumed with $100 \%$ error in retrieval. More details about the sensitivities of different a priori profiles will be discussed in Sect. 4.1.

The consecutive measured $\mathrm{O}_{4}$ DSCDs around the $360 \mathrm{~nm}$ band at different elevation angles serve as measurement vector for the HEIPRO algorithm. It is important to mention that the absorption of $\mathrm{O}_{4}$ simulated with the absorption cross section from Hermans et al. (2003) was previously reported with an underestimation of $25 \%$ and suggested to be scaled by multiplying it by 1.25 in several different aerosol retrieval schemes (Clémer et al., 2010; Großmann et al., 2013; Vlemmix et al., 2015). However, good agreement between modeled and measured $\mathrm{O}_{4}$ DSCDs in the Arctic is also achieved without any correction for the same $\mathrm{O}_{4}$ cross section (Frieß et al., 2011). In fact, varied correction factors to the retrieved $\mathrm{O}_{4}$ were applied depending on the uncertainty introduced by the absolute value of the $\mathrm{O}_{4}$ absorption cross section (Zieger et al., 2011). Here, the new cross section from Thalman and Volkamer (2013) is adopted to retrieve $\mathrm{O}_{4}$; therefore, we first need to include the appropriate scaling factor in the HEIPRO algorithm.

Consequently, a cloud-free day with low aerosol load (AOD < 0.15), i.e., 4 April 2015, was chosen to test different scaling factors for $\mathrm{O}_{4}$ absorption, under which the $\mathrm{O}_{4}$ DSCDs between 15 and $30^{\circ}$ elevation are sensitive to variations of atmospheric temperature and pressure, as well as the aerosol optical properties (Frieß et al., 2006; Wagner et al., 2009; Clémer et al., 2010). In the HEIPRO scheme, the scaling only takes effects on the modeled value by multiplying with the $\mathrm{O}_{4}$ cross section. Since Hermans et al. (2003) and Thalman and Volkamer (2013) present different $\mathrm{O}_{4}$ cross section values at $360 \mathrm{~nm}$, we test different scaling factors, 0.875 , 1.0, 1.125 and 1.25, within HEIPRO in order to find the most appropriate for the adopted Thalman and Volkamer (2013) cross section.

In Fig. 2, the modeled $\mathrm{O}_{4}$ absorption with different scaling factors was compared to the measured $\mathrm{O}_{4}$ differential optical depth (DOD, Frieß et al., 2006) at elevation angles of 10, 20 and $30^{\circ}$. It is obvious that the modeled $\mathrm{O}_{4}$ absorptions without scaling were systematically about $20 \%$ lower than the measured $\mathrm{O}_{4}$ at these elevations and even more during the morning periods. However, the modeled $\mathrm{O}_{4}$ absorption 


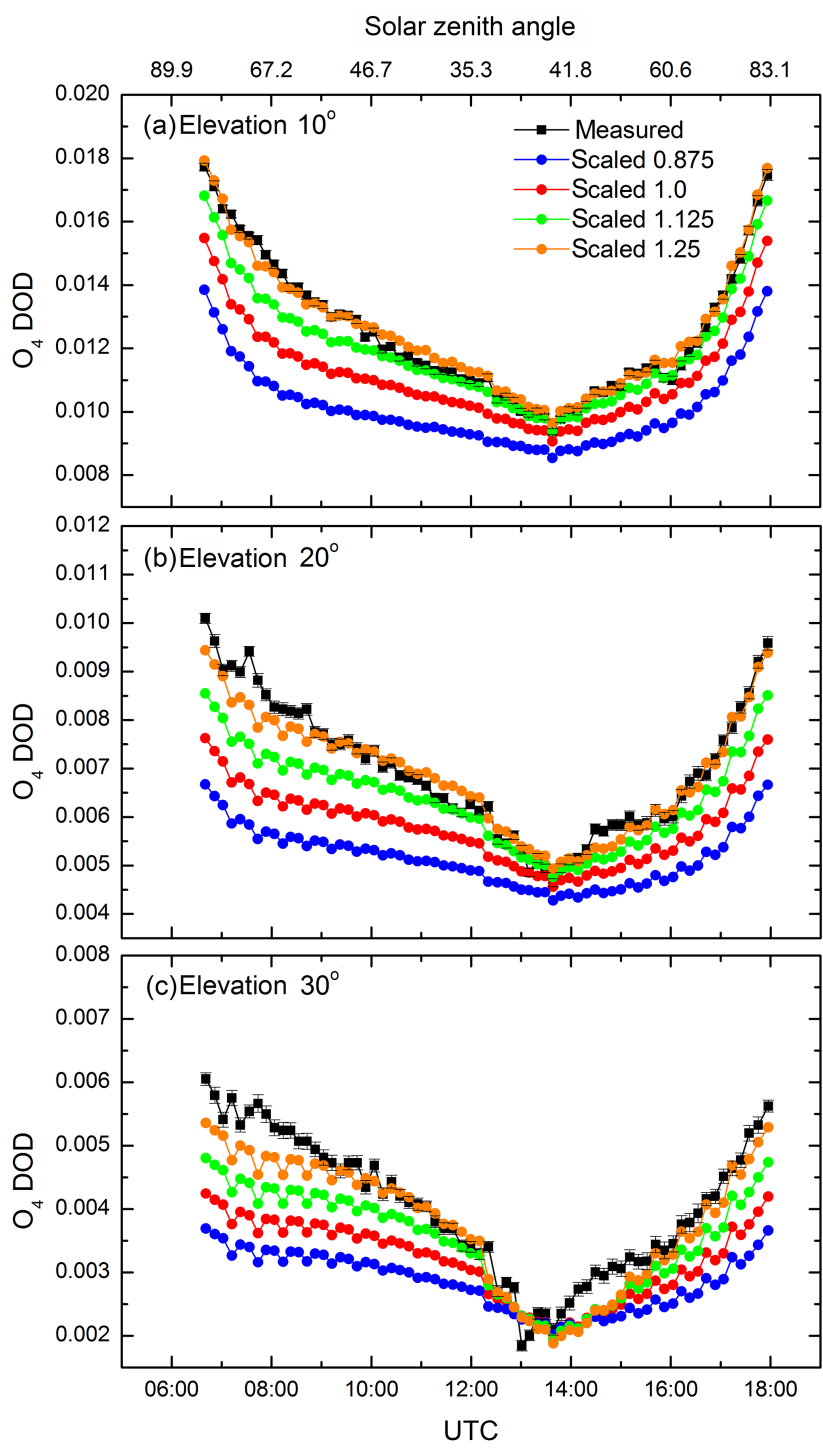

Figure 2. Diurnal variation of the measured $\mathrm{O}_{4}$ DODs and simulated $\mathrm{O}_{4}$ DODs with different scaling factors at elevation angles of 10, 20 and $30^{\circ}$ on 4 April 2015.

was overestimated with a scaling factor of 1.25 around noon and even at elevation angles lower than $10^{\circ}$, which was also found by Irie et al. (2015). In the following aerosol retrieval at $360 \mathrm{~nm}$, we assume a scaling factor of 1.2 as the optimal correction for the uncertainties from the newly available $\mathrm{O}_{4}$ cross section, which is comparable to those previously reported for scaling $\mathrm{O}_{4}$ from Hermans et al. (2003) (Wagner et al., 2009; Clémer et al., 2010).

\section{Results and discussion}

\subsection{Sensitivity to the a priori profile}

Since the information content of the measurement is usually too low to reconstruct a full state vector, additional information concerning the atmospheric state is provided by an a priori state vector $\boldsymbol{x}_{\mathrm{a}}$ with covariance matrix $\mathbf{S}_{\mathrm{a}}$. As an important input parameter, the a priori profile poses an additional constraint on the retrieved profile. Unfortunately, the impact of the a priori is substantial and there is no additional external information available that justifies the selection of one specific a priori profile (Vlemmix et al., 2015). To investigate the impacts of a priori profile shape, aerosol retrievals were performed with only four different a priori extinction profiles available in the HEIPRO algorithm, i.e., linear, exponential, Boltzmann (smoothed box-shaped) and Gaussian distribution (peaking shape), as plotted in Fig. 3a. The same cloud-free and low aerosol loading day of 4 April 2015 was chosen for the sensitivity study of different a priori profiles. Besides the input parameters in the forward model as mentioned in Sect. 3.2, other required observed geometry parameters were set according to the real measurements, e.g., solar zenith angle and relative azimuth angle.

Figure $3 \mathrm{~b}$ shows the comparison between measured and simulated $\mathrm{O}_{4}$ absorptions resulting from the different a priori extinction profiles. When a Gaussian a priori profile was applied, the simulated $\mathrm{O}_{4}$ absorption close to surface (elevation angle $1^{\circ}$ ) was much higher than the measured $\mathrm{O}_{4}$ absorption, and also resulted in underestimations at higher elevation angles. Except for the Gaussian a priori, there were only small differences in the modeled $\mathrm{O}_{4}$ absorptions among the other three a priori profiles. By estimating the degree of freedom for signal (DFS) and solution of cost function in the retrievals, the statistics indicates that better performance of larger DFS and smaller cost function were approached by utilizing an exponential a priori.

Considering the fact that the mass concentration profiles of the different aerosol types usually decrease with altitude in the lower troposphere, whereas the background profile in the free troposphere remains constant with altitude, we have adopted the exponentially decreasing shaped extinction profile as the a priori profile. We then test the appropriate scale height of an exponential a priori profile, which defines the decreases of aerosol concentration in the vertical. The results show that the retrieved aerosol was constrained within lower altitudes by the algorithm if the scale height was set to be too small, whereas large-scale height results in artifacts at higher altitudes. Therefore, a moderate scale height of $1.5 \mathrm{~km}$, where the aerosol extinction coefficient decreased to half of the surface value, was finally determined for the exponential a priori profile used in the aerosol retrieval. 

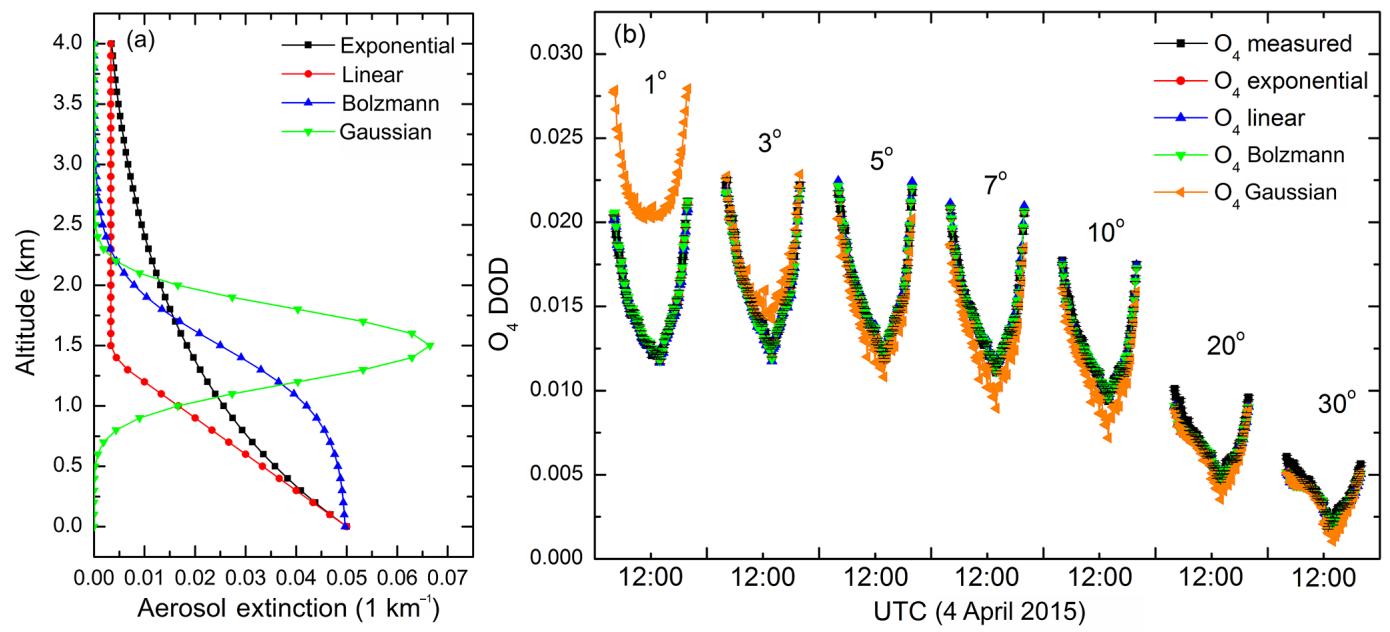

Figure 3. Different a priori aerosol extinction profiles as input (a) and relevant $\mathrm{O}_{4}$ DODs simulation compared with measured $\mathrm{O}_{4}$ DODs on 4 April 2015 (b).

\subsection{Aerosol optical characteristics}

To evaluate the performance of the MAX-DOAS retrieval, the AOD from the AERONET instrument at multiple wavelengths was interpolated to $360 \mathrm{~nm}$ using the Ångström coefficient $(\alpha)$ (see Eq. 3):

$\mathrm{AOD}=\beta \times \lambda^{-\alpha}$,

and then further averaged for hourly data series to be compared with the MAX-DOAS-retrieved AODs. Since AERONET data are automatically cloud-cleared, the hourly MAX-DOAS-retrieved AODs, which were calculated from the retrieved aerosol extinction profiles in the HEIPRO algorithm, are normalized to the timetable of AERONET data. Figure 4 shows the time series of hourly AODs inferred from the sun photometer and MAX-DOAS measurements for several months. AODs retrieved from these two methods exhibit similar temporal trends. The occasional occurrences of high AODs $(>0.2)$ were attributed to the influence of long-range transport of windblown dust from the Saharan area, marked as gray hatched areas in Fig. 4, which are further discussed as a case study in Sect. 4.4.

The monthly averaged time series of AODs retrieved from MAX-DOAS and AERONET, shown in Fig. 5, exhibit higher aerosol loadings from June to September 2015. These higher AODs in the summer season are mainly due to long-range transport of Saharan dust, which occurs more frequently in summer than in winter (Sicard et al., 2011). Moreover, good agreement exists in both hourly and monthly retrieved AODs between MAX-DOAS and AERONET, as high correlation coefficients of $R=0.87$ (number of datapoints $=618$, $\mathrm{AOD}_{\text {MAX-DOAS }}=0.6673 \times$ AOD $\left._{\text {AERONET }}+0.0294\right)$ and $R=0.96$ (number of datapoints $=7$, AOD $_{\mathrm{MAX} \text {-DOAS }}=$ $0.6253 \times \mathrm{AOD}_{\mathrm{AERONET}}+0.0362$ ), respectively, were obtained by linear regression. However, these two datasets
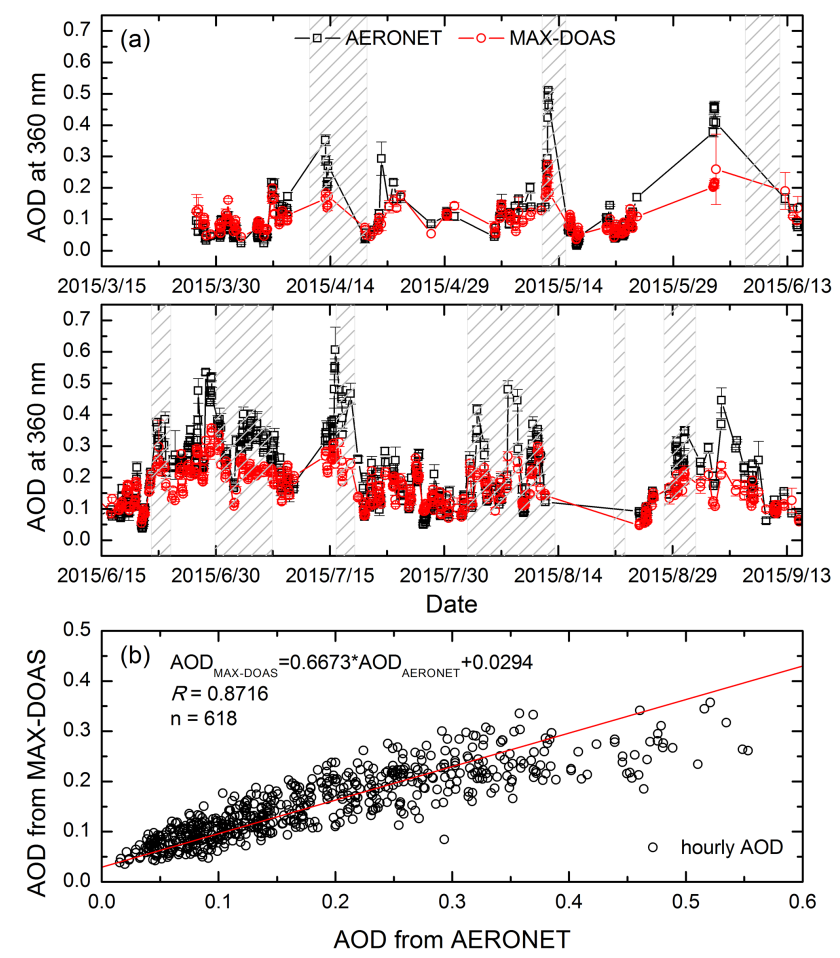

Figure 4. Time series of the AODs at $360 \mathrm{~nm}$ retrieved from MAXDOAS and AERONET.

usually do not compare so well in the case of higher aerosol loading, under which the absolute differences between the MAX-DOAS and AERONET are relatively larger (Fig. 4). The MAX-DOAS underestimation of the retrieved AOD could probably be explained by the constraint that only aerosol extinctions below $4 \mathrm{~km}$ were considered in the algorithm, especially for conditions of dust events when the 


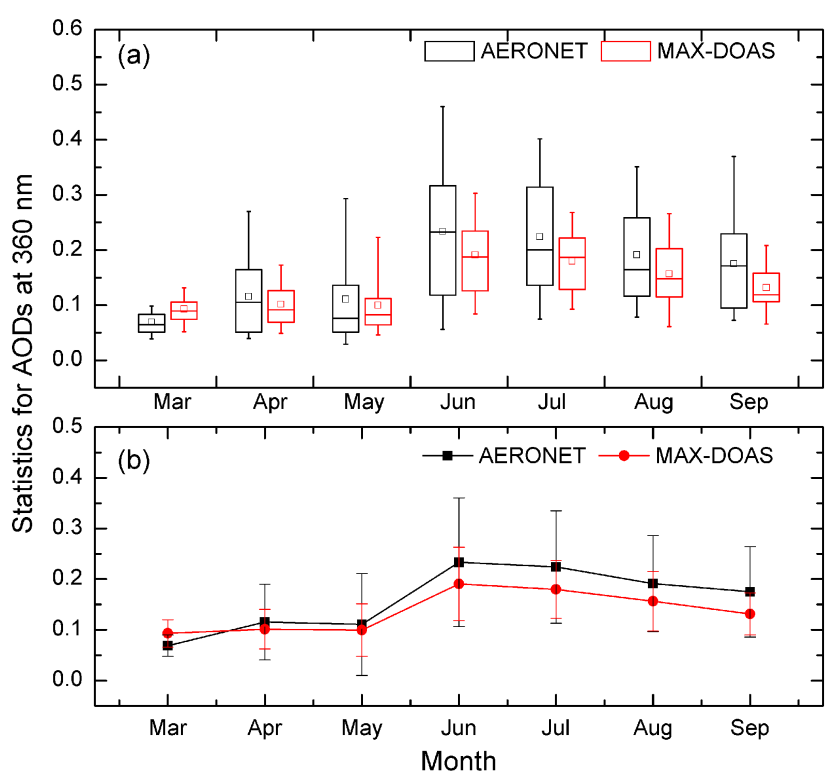

Figure 5. Statistics for monthly AODs at $360 \mathrm{~nm}$ retrieved from MAX-DOAS and AERONET. The upper and lower boundaries of box indicate the 1st and 3rd quartile respectively. The whiskers show the 5 th and 95 th percentiles. Mean and median are represented with open square and centerline in the box.

air mass can transport dust at higher altitudes. Furthermore, the exponentially decreasing a priori extinction profile poses strong constraints on aerosols at higher altitudes. Note also that the Saharan dust particles usually show the characteristic optical properties of the single scattering albedo, the asymmetry parameter and the Ångström coefficient, which are different to those introduced in the basic scenario of HEIPRO retrieval (Gkikas et al., 2013).

Generally, although a rather good correlation was obtained between MAX-DOAS retrieval and CIMEL instrument of AERONET, the deviation of these two datasets is still around $20 \%$. This is possibly due to an inhomogeneous horizontal distribution of aerosols. Note that the AERONET site was located in the northwest away from the MAX-DOAS instrument, whereas the telescope of MAX-DOAS points in a southern direction. As a consequence, the MAX-DOASretrieved aerosol extinction profiles are representative of an average over the light paths in the lower troposphere over several kilometers up to $15 \mathrm{~km}$ in the horizontal, which was roughly estimated based on the $\mathrm{O}_{4} \mathrm{SCD}$ at $0^{\circ}$ elevation (Sinreich et al., 2013; Wang et al., 2014).

\subsection{Surface aerosol extinction}

Owing to the absence of extinction coefficient measurements at ground surface and in the vertical, another semiquantitative way to validate the aerosol extinction coefficient retrieved by MAX-DOAS is to compare it with particle mass concentrations. As indicated in Fig. 1, surface $\mathrm{PM}_{2.5}$ concen- trations from six in situ stations were averaged to represent the aerosol loading throughout the entire city, which are then compared to the MAX-DOAS retrieval of surface aerosol extinction coefficient; i.e., the bottom layer below $100 \mathrm{~m}$ of the aerosol extinction profile was considered as being representative of the surface extinction. Figure 6 shows the comparison between surface aerosol extinction coefficient retrieved from MAX-DOAS and $\mathrm{PM}_{2.5}$ concentration measured with in situ instrumentation.

As shown in the upper panel of Fig. 6, a good agreement exists between the daily aerosol surface extinction coefficient from the MAX-DOAS retrievals and the ground $\mathrm{PM}_{2.5}$ concentration. This implies that the surface extinction coefficient obtained from MAX-DOAS retrieval truly reflects the number of particles near the ground. The linear fitting for aerosol extinction coefficient and particle mass concentration yielded a correlation coefficient $R$ of 0.89 in daily average and 0.64 in hourly average, respectively. Different explanations for the discrepancy in the hourly data include, firstly, that the regression analysis was based on the comparison between two different types of aerosol parameters and that the aerosol extinction coefficient ranged basically with particle mass concentration; however, it is also influenced by multiple factors including particles constituent, hygroscopicity and meteorological conditions (Zieger et al., 2011). Secondly, the in situ $\mathrm{PM}_{2.5}$ data were measured directly at or close to the surface, whereas the aerosol surface extinction coefficient was extracted from the MAX-DOAS-retrieved profile from ground to $100 \mathrm{~m}$, averaged over a large horizontal distance. As a consequence, the inhomogeneous distribution of particles, both in vertical and horizontal directions, decreases the consistency of these two data series (Frieß et al., 2016). It also should be mentioned that the whole retrieved dataset was included in Fig. 6c without cloud filtering.

We then evaluate the impacts of air mass transport on the surface extinction coefficient and $\mathrm{PM}_{2.5}$. The wind roses in Fig. 7a indicate that the AERONET AODs and retrieved surface extinction coefficient, as well as in situ $\mathrm{PM}_{2.5}$, generally exhibit a similar dependence on wind direction. As it can be seen in Fig. 7a, combined high $\mathrm{PM}_{2.5}$ concentrations but low surface extinction conditions are present when the winds blow from a S-SW-W direction. However, there was an inverse situation under northerly winds. In view of the specific geographic characteristics, i.e., the north of Madrid metropolitan is surrounded by mountains, the dispersion pathway of particles was significantly impacted by wind direction. Winds from $\mathrm{N}$ and $\mathrm{S}$ to $\mathrm{SW}$ components are dominant from March to September in Madrid; see Fig. 7b. Using regression analysis of hourly $\mathrm{PM}_{2.5}$ and the surface extinction coefficient for 16 different wind directions, correlation coefficients are found to be lower for northeastern winds along with calm conditions, suggesting that the particles transported from the northeast show different extinction properties to those from other wind directions. 

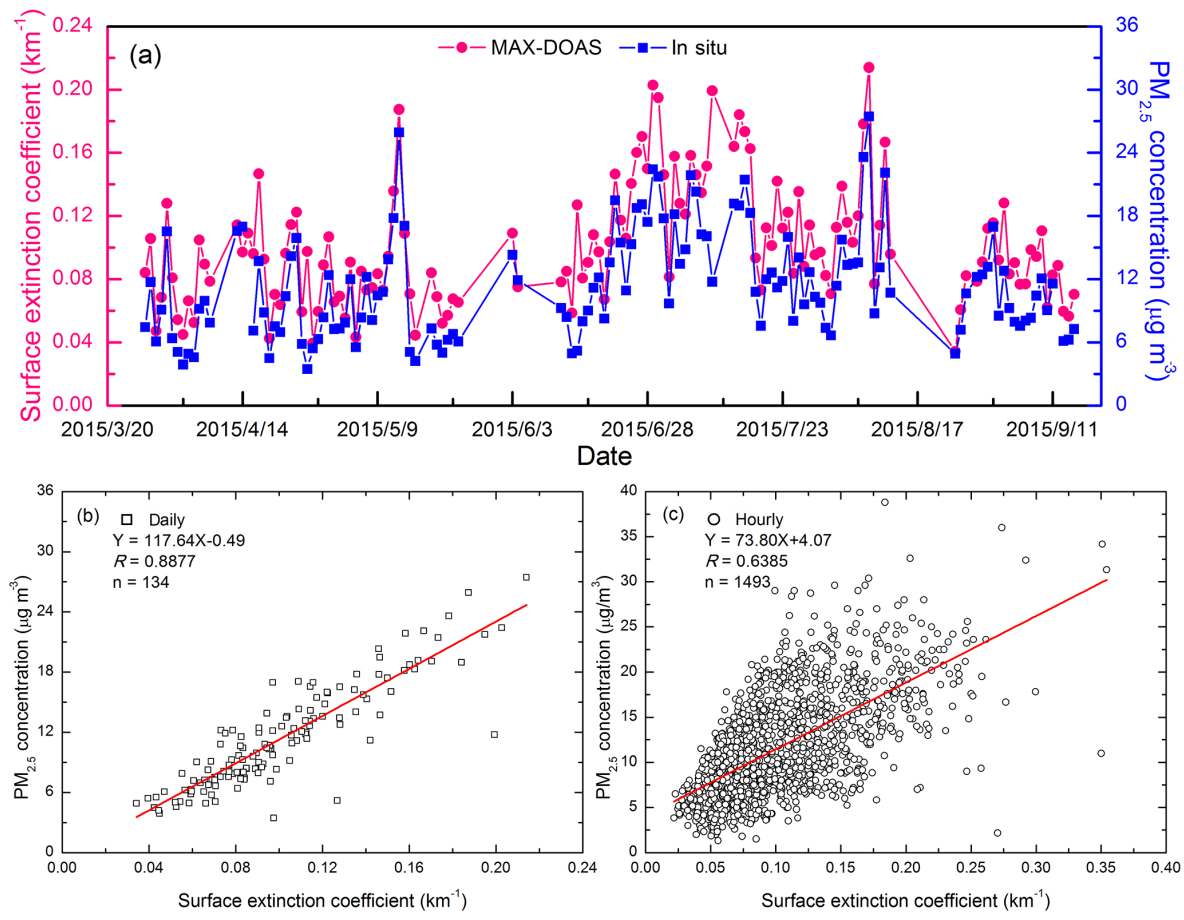

Figure 6. Time series of surface aerosol extinction coefficient retrieved from MAX-DOAS and comparison with in situ PM 2.5 concentration (a). Linear regression plots of daily and hourly data are shown in (b) and (c), respectively.
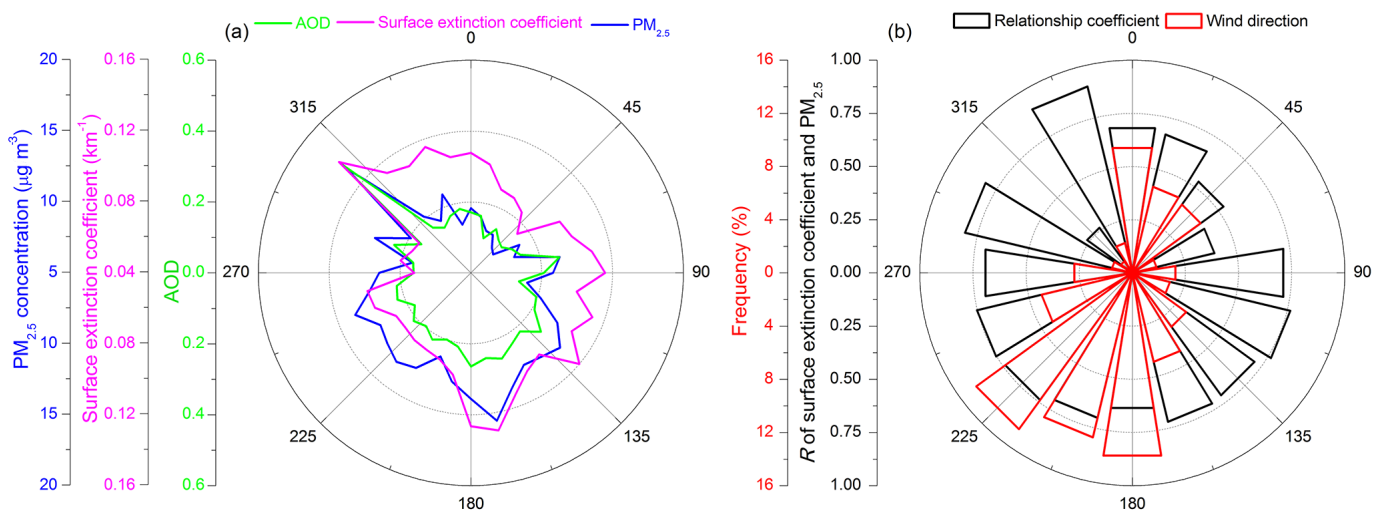

Figure 7. Wind roses of AOD (a), surface aerosol extinction coefficient and $\mathrm{PM}_{2.5}$ as a function of wind direction. (b) shows the frequency and the dependence of regression coefficient between surface extinction coefficient and $\mathrm{PM}_{2.5}$ on wind direction.

\subsection{Case study of Saharan dust intrusion}

Previous studies showed that the transport of Sahara dust resulted in high levels of aerosol pollution in the Iberian Peninsula including the city of Madrid, while the Atlantic or polar air masses generally bring cleaner air, significantly reducing particulate matter levels (Querol et al., 2009; Díaz et al., 2012). During the period of MAX-DOAS measurements, several Saharan dust intrusions affecting Madrid were reported by the Directorate-General of Environmental Quality and Assessment (Dirección General de Calidad y Evaluación Ambiental) at the Ministry of Agriculture, Food and Environment (Ministerio de Agricultura, Alimentación y Medio Ambiente ${ }^{1}$ ), as also shown in Fig. 4. The diagnosis of Saharan dust intrusions uses an integrated approach based on data from back-trajectory analysis (Hysplit model, http://www.ready.noaa.gov), simulated dust maps from the NRL (http://www.nrlmry.navy.mil/aerosol/), SKIRON (http://forecast.uoa.gr/forecastnewinfo.php) and BSCDREAM (http://www.bsc.es/) models and satellite images

\footnotetext{
${ }^{1}$ http://www.magrama.gob.es/es/calidad-y-evaluacionambiental/temas/atmosfera-y-calidad-del-aire/calidad-delaire/gestion/Prediccion_episodios_2015.aspx
} 

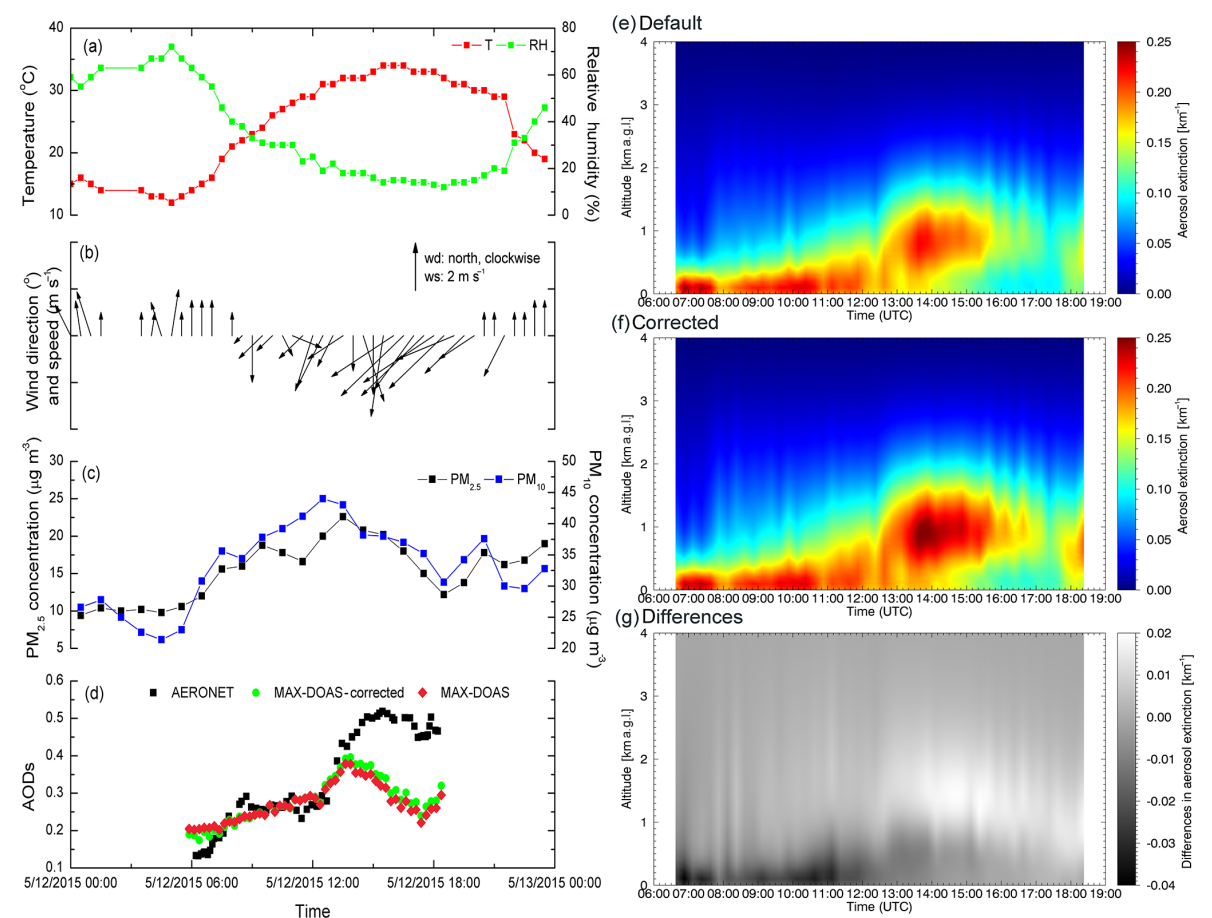

Figure 8. Diurnal variation of meteorological parameters (a) and (b), in situ particle concentrations (c) and MAX-DOAS-retrieved AOD (d) and aerosol extinction profiles for a dust intrusion case study on 12 May 2015. Aerosol extinction profiles with default setting and corrected with AERONET products are shown in (e) and (f), respectively. (g) shows the difference of aerosol extinction between (e) and (f) (corrected - default).

provided by the NASA SeaWiFS project, as described in Díaz et al. (2012).

To investigate the capability of MAX-DOAS retrieval for dust intrusion, we use a case study focusing on the most severe dust intrusion with extremely high AOD up to 0.5, which occurred on 12 May 2015. Figure 8a and b displayed the meteorological parameters during this episode, including temperature, relative humidity and wind direction and speed. It can be found that the wind direction changed from northern to southern directions around 09:00 UTC on that day, while both $\mathrm{PM}_{2.5}$ and $\mathrm{PM}_{10}$ concentration, as well as AOD, increased to high levels that lasted for the following few hours. Together with high AOD, the arrival of the dry air mass is correlated with a relative humidity decline from 30 to $15 \%$. Therefore, all these characteristics identified this day as a typical Saharan dust intrusion event.

The Angström coefficient, single scattering albedo and asymmetry parameters, as extracted from the AERONET product, are used to represent the characteristic optical properties of Saharan dust vs. those of local aerosols. Figure 8e and $f$ depict the initial retrieved aerosol profile and the corrected profile after including the characteristic aerosol optical properties (i.e., single scattering albedo and asymmetry parameters) of Saharan dust, as registered by AERONET, in HEIPRO. The results show small differences in both retrievals. Both of them capture the elevation of high aerosol extinction between 13:00 and 16:00 UTC. The good performance of the MAX-DOAS retrieval is validated by the air mass pathways shown in Fig. 9, which provides information on possible aerosol sources and the advective transport towards the Iberian Peninsula during the dust event. As demonstrated in Fig. 9a, the $48 \mathrm{~h}$ backward trajectory that arrived in Madrid at 15:00 UTC on 12 May denotes that the air mass at $1500 \mathrm{~m}$ above ground level (a.g.l.) is from the southwest, accompanied with an elevation of several hundred meters in the vertical, which was also captured by the MAX-DOASretrieved extinction profiles.

The initial and corrected AODs retrieved from MAXDOAS, together with the AERONET AOD, are shown in Fig. 8d. The agreement between MAX-DOAS and AERONET datasets was only slightly improved with the correction for aerosol optical parameters. However, the AOD was not improved as much as expected after 14:00 UTC. The remaining systematic underestimation of AOD is likely due to the fact that the algorithm was constrained for aerosol extinction within the first $4 \mathrm{~km}$ and has a lower sensitivity for high altitudes (Frieß et al., 2016). The backward trajectory of the air mass at $3000 \mathrm{~m}$ a.g.l. reveals that dust from the southwest at even higher altitudes passed over Madrid (Fig. 9a). This may explain the underestimation of MAXDOAS AODs, with respect to AERONET (Fig. 5), during days of Saharan dust intrusions, since during these events, 


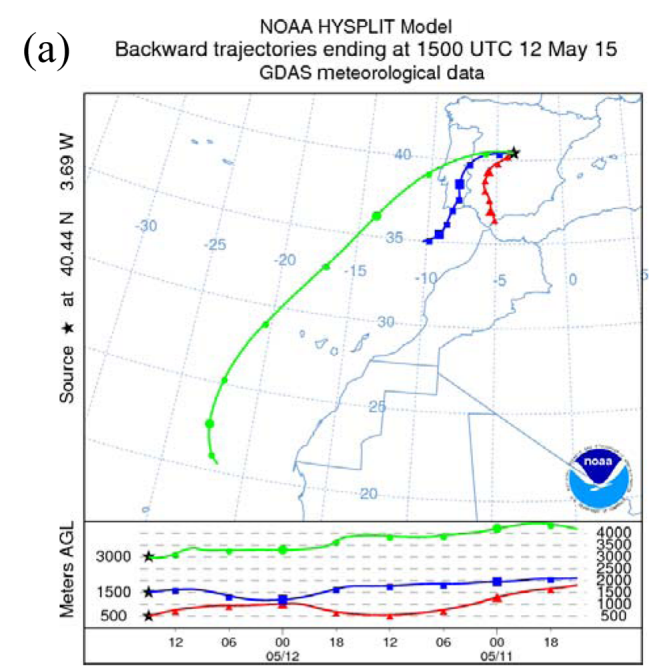

NAAPS dust optical depth, $700 \mathrm{mb}$ winds for 2015051212 (i.e. dust loading of $50,300,750,1500$ and $4500 \mathrm{mg} / \mathrm{m} * * 2$ )

(c)

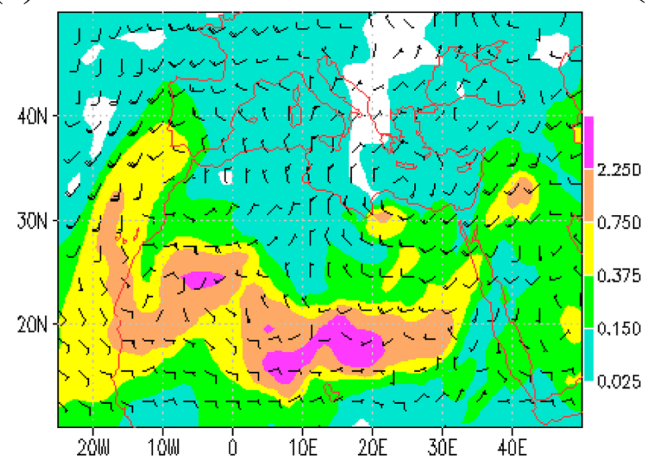

(b) NAAPS dust optical depth, $700 \mathrm{mb}$ winds for 2015051206
(i.e., dust loading of $50,300,750,1500$ and $4500 \mathrm{mg} / \mathrm{m} * * 2$ )

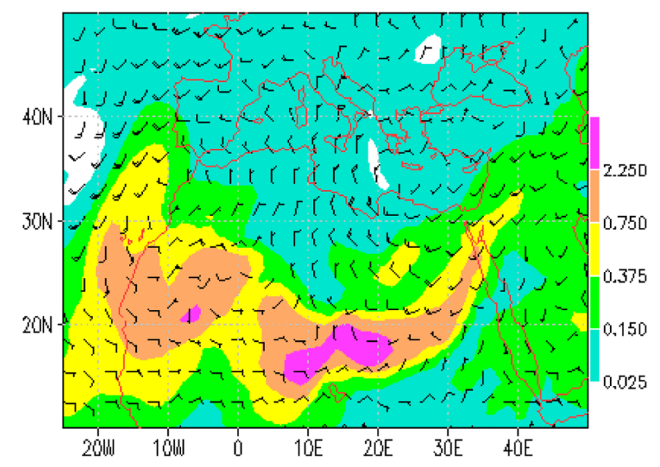

NAAPS dust optical depth, $700 \mathrm{mb}$ winds for 2015051218 (i.e., dust loading of $50,300,750,1500$ and $4500 \mathrm{mg} / \mathrm{m} * * 2$ )

(d)

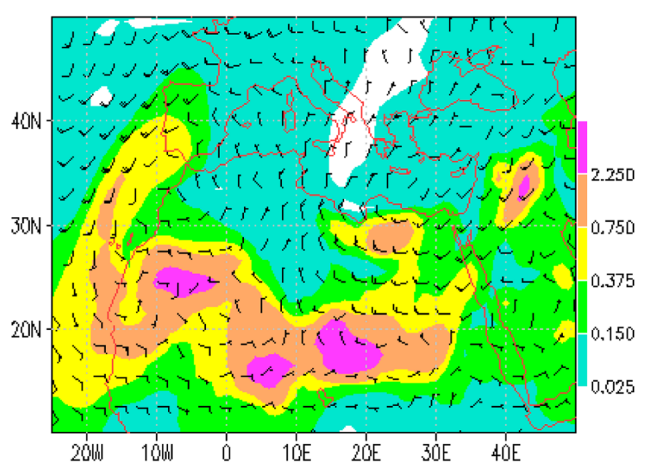

Figure 9. Air mass pathway analysis: (a) $48 \mathrm{~h}$ back-trajectories arriving in Madrid at 15:00 UTC and NAAPS modeled dust optical depth at (b) 06:00, (c) 12:00 and (d) 18:00 UTC on 12 May 2015 from NRL.

the contribution of the partial optical depth above $4 \mathrm{~km}$ to the total AOD is much higher than during typical nonintrusion days. Further details of the dust intrusion are provided by the dust optical depth at $550 \mathrm{~nm}$ at 06:00, 12:00 and 18:00 UTC on 12 May (Fig. 9b, c and d), which was modeled by the Navy Aerosol Analysis and Prediction System (NAAPS) provided by Naval Research Laboratory (NRL). This confirms that the Saharan dust arrived in Madrid around 12:00 UTC and lasted the whole afternoon.

Considering the ability to capture the elevated layer, the Gaussian a priori profile was attempted in order to retrieve the aerosol extinction profile of this dusty day. As it can be seen in Fig. 3a, the Gaussian profile was distributed as a peaking shape, which was defined and parameterized in the algorithm with two variables, i.e., the aerosol extinction coefficient of the peak and the altitude of the peak. However, the bottom of the Gaussian profile close to the ground surface has an extremely low aerosol extinction coefficient, which obviously deviates from the realistic condition that considerable aerosol loaded within low altitude during dust days.
Therefore, the modeled $\mathrm{O}_{4}$ optical depths deviate from the measurements. It implies that this simplified Gaussian a priori is not suitable for the dust layer retrieval. More suitable a priori profile for the elevated plumes retrieval deserves further investigation along with other satellite and ground-based measurement in the future.

\section{Summary and conclusions}

In this paper, we present the retrieval of aerosol extinction coefficient and resulting AODs from MAX-DOAS measurements carried out from March to September 2015 in the urban area of Madrid. The $\mathrm{O}_{4}$ absorption in the UV bands at multiple elevations angles served as input for the HEIPRO algorithm to retrieve aerosol extinction profiles in the lower troposphere. Based on tests for $\mathrm{O}_{4}$ absorption correction, a cross section scaling factor of 1.2 was determined as the optimal correction for the uncertainties arising from the inclusion of the newly available $\mathrm{O}_{4}$ cross section measured by Thal- 
man and Volkamer (2013) in the aerosol retrieval at $360 \mathrm{~nm}$. The influence of different types of a priori profiles on the retrieval, i.e., linear, exponential, Boltzmann (smoothed boxshaped) and Gaussian distribution (peaking shape), was investigated, which suggests that an exponential a priori profile with a moderate scale height of $1.5 \mathrm{~km}$ is suitable for use in this typical urban site.

Retrieved hourly AODs at $360 \mathrm{~nm}$ from MAX-DOAS were compared to the correlative AERONET sun photometer product. Both of them displayed a similar temporal behavior with significant correlation coefficients, with an $R$ of 0.87. Due to the more frequent Saharan dust intrusions in summer, monthly mean AODs showed highest values from June to September. Nevertheless, a deviation of $20 \%$ exists between these two datasets, especially during high aerosol loading conditions (AOD $>0.2$ ), e.g., dust intrusions. The MAX-DOAS-retrieved surface aerosol extinction coefficient was also compared to the averaged $\mathrm{PM}_{2.5}$ concentrations from six urban in situ stations. The good agreement between both datasets indicates that the MAX-DOAS retrieval is an effective tool to characterize the number of particles close to the surface. In addition, the retrieved AOD and surface extinction coefficient, as well as in situ $\mathrm{PM}_{2.5}$, exhibit a generally similar dependence on wind direction.

A severe dust intrusion on 12 May 2015 was chosen to assess the capability of the MAX-DOAS retrieval during dust events. The high performance of MAX-DOAS retrieval to recognize the elevated layer of particles was aided by airmass backward trajectory analysis. After removing the uncertainties from the Ångström coefficient, single scattering albedo and asymmetry parameters, the absolute difference in AODs between the MAX-DOAS and AERONET methods was mainly attributed to the low sensitivity of the MAXDOAS inversion algorithm to the partial optical depth above $3-4 \mathrm{~km}$. Finally, we suggest that the ability of the MAXDOAS technique to retrieve information on the vertical distribution of the aerosol extinction coefficient over long periods of time provides an additional tool for the study of the air quality in Madrid. More comprehensive and direct validation of the MAX-DOAS-retrieved aerosol extinction profiles needs simultaneous combined ancillary measurements, e.g., by lidars and ceilometers.

Acknowledgements. The research leading to these results has received funding from the European Community's Seventh Framework Programme (FP7/2007-2013) under grant agreement no. 607405 (QA4ECV project). Sincere thanks are expressed for the financial support from the National Natural Science Foundation of China (no. 41405117). We thank Juan Ramon Moreta Gonzalez (principal investigator) and their staff for establishing and maintaining the Madrid AERONET site used in this paper. The authors gratefully acknowledge the NOAA Air Resources Laboratory (ARL) for the provision of the HYSPLIT transport and dispersion model used in this publication. We acknowledge the use of Navy Aerosol Analysis Prediction System (NAAPS) model results provided by the Naval Research Laboratory (NRL) in Monterey, CA.

Edited by: P. Stammes

Reviewed by: two anonymous referees

\section{References}

Ayuntamiento de Madrid (AM): Madrid's Air Quality Plan 20112015, General Directorate of Sustainability, Government Division of Environment, Safety and Mobility, Madrid City Council, 2012.

Chance, K. and Kurucz, R. L.: An improved high-resolution solar reference spectrum for Earth's atmosphere measurements in the ultraviolet, visible, and near infrared, http://www.cfa.harvard. edu/atmosphere (last access: October 2015), 2010

Clémer, K., Van Roozendael, M., Fayt, C., Hendrick, F., Hermans, C., Pinardi, G., Spurr, R., Wang, P., and De Mazière, M.: Multiple wavelength retrieval of tropospheric aerosol optical properties from MAXDOAS measurements in Beijing, Atmos. Meas. Tech., 3, 863-878, doi:10.5194/amt-3-863-2010, 2010.

Dirección General de Sostenibilidad y Planificación de la Movilidad: Calidad de Aire Madrid 2014, 2014.

Díaz, J., Tobías, A., and Linares, C.: Saharan dust and association between particulate matter and case-specific mortality: a casecrossover analysis in Madrid (Spain), Environ. Health, 11, 1-6, doi:10.1186/1476-069X-11-11, 2012.

Fernández, A. J., Molero, F., and Pujadas, M.: Aerosol optical and microphysical properties observed by the lidar technique from a forest-fire smoke event over Madrid, Int. J. Remote Sens., 35, 5004-5035, doi:10.1080/01431161.2014.934405, 2014.

Fleischmann, O. C., Hartmann, M., Burrows, J. P., and Orphal, J.: New ultraviolet absorption cross-sections of $\mathrm{BrO}$ at atmospheric temperatures measured by a time-windowing Fourier transform spectroscopy, J. Photoch. Photobio. A, 168, 117-132, 2004.

Frieß, U., Monks, P. S., Remedios, J. J., Rozanov, A., Sinreich, R., Wagner, T., and Platt, U.: MAX-DOAS $\mathrm{O}_{4}$ measurements: A new technique to derive information on atmospheric aerosols: 2. Modeling studies, J. Geophys. Res., 111, D14203, doi:10.1029/2005JD006618, 2006.

Frieß, U., Sihler, H., Sander, R., Pöhler, D., Yilmaz, S., and Platt, U.: The vertical distribution of $\mathrm{BrO}$ and aerosols in the Arctic: Measurements by active and passive differential optical absorption spectroscopy, J. Geophys. Res., 116, D00R04, doi:10.1029/2011JD015938, 2011.

Frieß, U., Klein Baltink, H., Beirle, S., Clémer, K., Hendrick, F., Henzing, B., Irie, H., de Leeuw, G., Li, A., Moerman, M. M., van Roozendael, M., Shaiganfar, R., Wagner, T., Wang, Y., Xie, P., Yilmaz, S., and Zieger, P.: Intercomparison of aerosol extinction profiles retrieved from MAX-DOAS measurements, Atmos. Meas. Tech., 9, 3205-3222, doi:10.5194/amt-9-3205-2016, 2016.

Gkikas, A., Hatzianastassiou, N., Mihalopoulos, N., Katsoulis, V., Kazadzis, S., Pey, J., Querol, X., and Torres, O.: The regime of intense desert dust episodes in the Mediterranean based on contemporary satellite observations and ground measurements, Atmos. Chem. Phys., 13, 12135-12154, doi:10.5194/acp-1312135-2013, 2013. 
Großmann, K., Frieß, U., Peters, E., Wittrock, F., Lampel, J., Yilmaz, S., Tschritter, J., Sommariva, R., von Glasow, R., Quack, B., Krüger, K., Pfeilsticker, K., and Platt, U.: Iodine monoxide in the Western Pacific marine boundary layer, Atmos. Chem. Phys., 13, 3363-3378, doi:10.5194/acp-13-3363-2013, 2013.

Hartl, A. and Wenig, M. O.: Regularisation model study for the least-squares retrieval of aerosol extinction time series from UV/VIS MAX-DOAS observations for a ground layer profile parameterisation, Atmos. Meas. Tech., 6, 1959-1980, doi:10.5194/amt-6-1959-2013, 2013.

Hendrick, F., Müller, J.-F., Clémer, K., Wang, P., De Mazière, M., Fayt, C., Gielen, C., Hermans, C., Ma, J. Z., Pinardi, G., Stavrakou, T., Vlemmix, T., and Van Roozendael, M.: Four years of ground-based MAX-DOAS observations of HONO and $\mathrm{NO}_{2}$ in the Beijing area, Atmos. Chem. Phys., 14, 765-781, doi:10.5194/acp-14-765-2014, 2014.

Hermans, C., Vandaele, A. C., Fally, S., Carleer, M., Colin, R., Coquart, B., Jenouvrier, A., and Mérienne, M.-F.: Absorption crosssection of the collision-induced bands of oxygen from the UV to the NIR, Proceedings of the NATO Advanced Research Workshop, Weakly Interacting Molecular Pairs: Unconventional Absorbers of Radiation in the Atmosphere, Fontevraud, France, 24 April-2 May 2002, edited by: Camy-Peyret, C. and Vigasin, A. A., NATO Science Series IV Earth and Environmental Sciences, Vol. 27, Kluwer Academic Publishers, Boston, 193-202, 2003.

Holben, B. N., Eck, T. F., Slutsker, I., Tanré, D., Buis, J. P., Setzer, A., Vermote, E., Reagan, J. A., Kaufman, Y. J., Nakajima, T., Lavenu, F., Jankowiak, I., and Smirnov, A.: AERONET - a federated instrument network and data archive for aerosol characterization, Remote Sens. Environ., 66, 1-16, 1998.

Hönninger, G., von Friedeburg, C., and Platt, U.: Multi axis differential optical absorption spectroscopy (MAX-DOAS), Atmos. Chem. Phys., 4, 231-254, doi:10.5194/acp-4-231-2004, 2004.

Intergovernmental Panel on Climate Change (IPCC): Climate change 2013: the physical science basis, in: Contribution of working group I to the fifth assessment report of the intergovernmental panel on climate change, edited by: Stocker, T. F., Qin, D., Plattner, G.-K., Tignor, M., Allen, S. K., Boschung, J., Nauels, A., Xia, Y., Bex, V., and Midgley, P. M., Cambridge University Press, Cambridge, UK, New York, NY, USA, 2013.

Irie, H., Kanaya, Y., Akimoto, H., Iwabuchi, H., Shimizu, A., and Aoki, K.: First retrieval of tropospheric aerosol profiles using MAX-DOAS and comparison with lidar and sky radiometer measurements, Atmos. Chem. Phys., 8, 341-350, doi:10.5194/acp-8341-2008, 2008.

Irie, H., Kanaya, Y., Akimoto, H., Iwabuchi, H., Shimizu, A., and Aoki, K.: Dual-wavelength aerosol vertical profile measurements by MAX-DOAS at Tsukuba, Japan, Atmos. Chem. Phys., 9, 2741-2749, doi:10.5194/acp-9-2741-2009, 2009.

Irie, H., Nakayama, T., Shimizu, A., Yamazaki, A., Nagai, T., Uchiyama, A., Zaizen, Y., Kagamitani, S., and Matsumi, Y.: Evaluation of MAX-DOAS aerosol retrievals by coincident observations using CRDS, lidar, and sky radiometer inTsukuba, Japan, Atmos. Meas. Tech., 8, 2775-2788, doi:10.5194/amt-82775-2015, 2015.

Karanasiou, A., Moreno, N., Moreno, T., Viana, M., de Leeuw, F., and Querol, X.: Health effects from Sahara dust episodes in Europe: Literature review and research gaps, Environ. Int., 47, 107114, doi:10.1016/j.envint.2012.06.012, 2012.
Kim, D. and Ramanathan V.: Solar radiation budget and radiative forcing due to aerosols and clouds, J. Geophys. Res., 113, D02203, doi:10.1029/2007JD008434, 2008.

Levy II, H., Horowitz, L. W., Schwarzkopf, M. D., Ming, Y., Golaz, J.-C., Naik, V., and Ramaswamy V.: The roles of aerosol direct and indirect effects in past and future climate change, J. Geophys. Res.-Atmos., 118, 4521-4532, doi:10.1002/jgrd.50192, 2013.

Li, X., Brauers, T., Shao, M., Garland, R. M., Wagner, T., Deutschmann, T., and Wahner, A.: MAX-DOAS measurements in southern China: retrieval of aerosol extinctions and validation using ground-based in-situ data, Atmos. Chem. Phys., 10, 2079 2089, doi:10.5194/acp-10-2079-2010, 2010.

Mahajan, A. S., Gómez Martín, J. C., Hay, T. D., Royer, S.-J., Yvon-Lewis, S., Liu, Y., Hu, L., Prados-Roman, C., Ordóñez, C., Plane, J. M. C., and Saiz-Lopez, A.: Latitudinal distribution of reactive iodine in the Eastern Pacific and its link to open ocean sources, Atmos. Chem. Phys., 12, 11609-11617, doi:10.5194/acp-12-11609-2012, 2012.

Meller, R. and Moortgat, G. K.: Temperature dependence of the absorption cross sections of formaldehyde between 223 and $323 \mathrm{~K}$ in the wavelength range $225-375 \mathrm{~nm}$, J. Geophys. Res., 105, 7089-7101, 2000.

Molero, F., Andrey, F. J., Fernandez, A. J., Parrondo, M. C., Pujadas, M., Córdoba-Jabonero, C., Revuelta, M. A. and GomezMoreno, F. J.: Study of vertically resolved aerosol properties over an urban background site in Madrid (Spain), Int. J. Remote Sens., 35, 2311-2326, 2014.

Platt, U. and Stutz, J.: Differential Optical Absorption Spectroscopy (DOAS), Principles and Applications, ISBN 978-3-540-21193-8, Springer, Berlin-Heidelberg, 2008.

Plaza, J., Pujadas, M., Gómez-Moreno, F. J., Sánchez, M., and Artíñana, B.: Mass size distributions of soluble sulfate, nitrate and ammonium in the Madrid urban aerosol, Atmos. Environ., 45, 4966-4976, 2011.

Prados-Roman, C., Cuevas, C. A., Hay, T., Fernandez, R. P., Mahajan, A. S., Royer, S.-J., Galí, M., Simó, R., Dachs, J., Großmann, K., Kinnison, D. E., Lamarque, J.-F., and Saiz-Lopez, A.: Iodine oxide in the global marine boundary layer, Atmos. Chem. Phys., 15, 583-593, doi:10.5194/acp-15-583-2015, 2015.

Querol, X., Pey, J., Pandolfi, M., Alastuey, A., Cusack, M., Pérez, N., Moreno, T., Viana, M., Mihalopoulos, N., Kallos, G., and Kleanthous, S.: African dust contributions to mean ambient $\mathrm{PM}_{10}$ mass-levels across the Mediterranean Basin, Atmos. Environ., 43, 4266-4277, doi:10.1016/j.atmosenv.2009.06.013, 2009.

Rodgers, C. D.: Inverse methods for atmospheric sounding: Theory and practice, World Scientific, Singapore, 2000.

Rozanov, A., Bovensmann, H., Bracher, A., Hrechanyy, S., Rozanov, V., Sinnhuber, M., Stroh, F., and Burrows, J.: $\mathrm{NO}_{2}$ and $\mathrm{BrO}$ vertical profile retrieval from SCIAMACHY limb measurements: Sensitivity studies, Adv. Space Res., 36, 846-854, doi:10.1016/j.asr.2005.03.013, 2005.

Salvador, P., Artíñano, B., Querol, X., and Alastuey, A.: A combined analysis of backward trajectories and aerosol chemistry to characterise long-range transport episodes of particulate matter: The madrid air basin, a case study, Sci. Total Environ., 390, 495506, 2008.

Seinfeld, J. H. and Pandis, S. N.: Atmospheric chemistry and physics: From air pollution to climate change, 2nd Edn., John Wiley and Sons, Hoboken, NJ, 2006. 
Serdyuchenko, A., Gorshelev, V., Weber, M., Chehade, W., and Burrows, J. P.: High spectral resolution ozone absorption crosssections - Part 2: Temperature dependence, Atmos. Meas. Tech., 7, 625-636, doi:10.5194/amt-7-625-2014, 2014.

Sicard, M., Rocadenbosch, F., Reba, M. N. M., Comerón, A., Tomás, S., García-Vízcaino, D., Batet, O., Barrios, R., Kumar, D., and Baldasano, J. M.: Seasonal variability of aerosol optical properties observed by means of a Raman lidar at an EARLINET site over Northeastern Spain, Atmos. Chem. Phys., 11, 175-190, doi:10.5194/acp-11-175-2011, 2011.

Sinreich, R., Merten, A., Molina, L., and Volkamer, R.: Parameterizing radiative transfer to convert MAX-DOAS dSCDs into near-surface box-averaged mixing ratios, Atmos. Meas. Tech., 6, 1521-1532, doi:10.5194/amt-6-1521-2013, 2013

Smirnov, A., Holben, B. N., Eck, T. F., Dubovik, O., and Slutsker, I.: Cloud screening and quality control algorithms for the AERONET database, Rem. Sens. Environ., 73, 337-349, 2000.

Thalman, R. and Volkamer, R.: Temperature dependent absorption cross-sections of $\mathrm{O}_{2}-\mathrm{O}_{2}$ collision pairs between 340 and $630 \mathrm{~nm}$ and at atmospherically relevant pressure, Phys. Chem. Chem. Phys., 15, 15371-15381, 2013.

Vandaele, A. C., Hermans, C., Simon, P. C., Carleer, M., Colins, R., Fally, S., Mérienne, M. F., Jenouvrier, A., and Coquart, B.: Measurements of the $\mathrm{NO}_{2}$ absorption cross-sections from $42000 \mathrm{~cm}^{-1}$ to $10000 \mathrm{~cm}^{-1}(238-1000 \mathrm{~nm})$ at $220 \mathrm{~K}$ and $294 \mathrm{~K}$, J. Quant. Spectrosc. Ra., 59, 171-184, 1998.

Viana, M., Pey, J., Querol, X., Alastuey, A., de Leeuw, F., and Anke Lükewille: Natural sources of atmospheric aerosols influencing air quality across Europe, Sci. Total Environ., 472, 825-833, 2014.

Vlemmix, T., Hendrick, F., Pinardi, G., De Smedt, I., Fayt, C., Hermans, C., Piters, A., Wang, P., Levelt, P., and Van Roozendael, M.: MAX-DOAS observations of aerosols, formaldehyde and nitrogen dioxide in the Beijing area: comparison of two profile retrieval approaches, Atmos. Meas. Tech., 8, 941-963, doi:10.5194/amt-8-941-2015, 2015.
Wagner T., Dix, B., von Friedeburg, C., Friess, U., Sanghavi, S., Sinreich, R., and Platt, U.: MAX-DOAS $\mathrm{O}_{4}$ measurements: A new technique to derive information on atmospheric aerosolsPrinciples and information content, J. Geophys. Res., 109, D22205, doi:10.1029/2004JD004904, 2004.

Wagner, T., Deutschmann, T., and Platt, U.: Determination of aerosol properties from MAX-DOAS observations of the Ring effect, Atmos. Meas. Tech., 2, 495-512, doi:10.5194/amt-2-4952009, 2009.

Wang, Y., Li, A., Xie, P. H., Wagner, T., Chen, H., Liu, W. Q., and Liu, J. G.: A rapid method to derive horizontal distributions of trace gases and aerosols near the surface using multi-axis differential optical absorption spectroscopy, Atmos. Meas. Tech., 7, 1663-1680, doi:10.5194/amt-7-1663-2014, 2014.

Wittrock, F., Oetjen, H., Richter, A., Fietkau, S., Medeke, T., Rozanov, A., and Burrows, J. P.: MAX-DOAS measurements of atmospheric trace gases in Ny-Ålesund - Radiative transfer studies and their application, Atmos. Chem. Phys., 4, 955-966, doi:10.5194/acp-4-955-2004, 2004.

Zieger, P., Weingartner, E., Henzing, J., Moerman, M., de Leeuw, G., Mikkilä, J., Ehn, M., Petäjä, T., Clémer, K., van Roozendael, M., Yilmaz, S., Frieß, U., Irie, H., Wagner, T., Shaiganfar, R., Beirle, S., Apituley, A., Wilson, K., and Baltensperger, U.: Comparison of ambient aerosol extinction coefficients obtained from in-situ, MAX-DOAS and LIDAR measurements at Cabauw, Atmos. Chem. Phys., 11, 2603-2624, doi:10.5194/acp11-2603-2011, 2011. 